\title{
A controlled trial of three referral methods for patients with third molars.
}

\author{
R. D. Goodey, ' M. R. Brickley, ${ }^{2}$ C. M. Hill, ${ }^{3}$ and J. P. Shepherd, ${ }^{4}$
}

\begin{abstract}
Aim To evaluate the accuracy, sensitivity and specificity of three primary to secondary care referral strategies.

Method Thirty two primary care dental practitioners (GDPs) were randomly allocated one of three referral strategies: current practice (control strategy); a neural network embedded within a computer program and a paper-based clinical algorithm. One hundred and seven patients were assessed for lower third molar treatment: 47, 30 and 30 in each group, respectively. Clinical details were assessed by a panel of experts against a gold standard for third molar removal (the National Institutes of Health criteria). The accuracy, sensitivity, specificity, positive and negative predictive values were calculated for each strategy. Results The referral decisions made by the GDPs in the control group displayed greater accuracy and sensitivity but poorer specificity $(0.83 ; 0.97 ; 0.22)$ compared with the neural network $(0.67 ; 0.56 ; 0.79)$ and clinical algorithm $(0.73 ; 0.56 ; 0.93)$.

Conclusions It was concluded that incorporation of the clinical algorithm into primary care was the most appropriate option. The computer neural network performed less well than either current practice or the clinical algorithm.
\end{abstract}

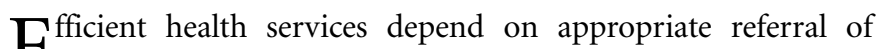
$\mathrm{E}_{\text {patients from primary to secondary care. Patients requiring }}$ specialist care in relation to their lower third molars are no exception. Whilst there has been effort to establish and validate criteria for lower third molar removal, ${ }^{1-4}$ particularly the recent report commissioned and published by the National Institute of Clinical Excellence (NICE), UK, ${ }^{5}$ few attempts have been made to evaluate and refine the referral process. Importantly, differences have been found between GDPs and oral surgeons in their ability to differentiate between third molars which should or should not be removed. ${ }^{6-13}$

The average NHS cost of a consultation with an oral surgeon, not including radiography costs was $\mathfrak{E} 13.75$ in 1994 . Since, in one month in 1995, 76\% of oral and maxillofacial surgeons practising in the UK received 8452 referrals for third molar assessment, ${ }^{14}$ consultation costs in that year could be estimated to be at least $\mathfrak{E} 1.4$ million. For $29 \%$ of these patients, surgery was not carried out, suggesting that expenditure of at least $£ 400 \mathrm{~K}$ could, potentially, have been avoided, assuming all removals were carried out appropriately. Apart from additional avoidable radiography costs in secondary care, this estimate does not include patient costs or GDP referral costs. These figures suggest that there is considerable poten-

$\overline{{ }^{1} \text { Research Fellow, }{ }^{2} \text { Clinical Lecturer, }{ }^{3} \text { Consultant Oral Surgeon, }{ }^{4} \text { Professor of Oral }}$ and Maxillofacial Surgery, Clinical Decisions Research Group, Department of Oral Surgery, Medicine and Pathology, University of Wales College of Medicine, Dental School, Heath Park, Cardiff, CF14 4XY

${ }^{*}$ Correspondence to: J. P. Shepherd

REFEREED PAPER

Received 22.02.00; Accepted 26.06.00

(C) British Dental Journal 2000; 189: 556-560 tial to refine the referral process to minimise avoidable cost and to maximise efficiency.

The purpose of this controlled trial was to evaluate the accuracy, sensitivity and specificity of three alternative referral strategies: current practice and two novel strategies.

\section{Methods}

One half of all GDPs $(n=112)$ in one district health authority (DHA) who referred patients to a hospital oral surgery department were contacted regarding participation in the trial. Forty four agreed to participate: 25 stated that they did not wish to participate and 43 did not respond. The consenting GDPs were randomly assigned to one of the three referral strategy groups. Homogeneity between the resulting three groups was assessed in terms of GDPs' gender, age, year of graduation from dental school and previous experience in hospital oral surgery. This information was collected using a postal questionnaire. Twelve GDPs failed to respond to this questionnaire. As a result the sample of participating GDPs was reduced to 32 , an overall recruitment rate of $29 \%$ (see table 1 ). The three decision strategies were current practice, a neural network based computer program ${ }^{15}$ and a paper-based clinical flowchart (clinical algorithm). The neural network was chosen as it had been developed by two of the authors (MRB, JPS), whereas the paperbased flowchart was chosen as it was a simple and cheap alternative.

\section{The neural network based computer program}

The Third Molar Decision Support System (Neural Computing Services - Version 5; Southampton) is a computer package incorporating a neural network trained to make decisions about whether or not lower third molars should be removed. The system consists of two programs that run concurrently: the Lower Third Molar Decision Support System (MODISS) and Neurun. MODISS forms the interface of the system and enables the assessment and recommendation to be displayed on a monitor. This software is linked to and assisted by Neurun, a trained neural network, the development of which has previously been reported. ${ }^{15}$ Once the patient's clinical details have been entered into the package, it takes just a few seconds for the package to provide a recommendation regarding the need for surgery.

\section{The clinical algorithm}

The clinical algorithm is a flowchart, which incorporates the NIH criteria. ${ }^{1}$ It was designed by an expert panel consisting of two oral surgeons, a GDP and a researcher with extensive knowledge of the criteria. The panel arranged the clinical criteria into the order in which they would be considered in a typical general dental examination. Ordering was transformed into a flowchart using Microsoft PowerPoint (Fig. 1). The end points of the flowchart were advice either to refer or not to refer. The algorithm was concerned exclusively with whether or not third molars should be removed. Other reasons for referral, such as surgical difficulty, requests for general 
Table I Numbers of GDPs by age, gender, qualifications, experience and years in practice

\begin{tabular}{llllll}
\hline Variable & Control & $\begin{array}{c}\text { Neural } \\
\text { Network }\end{array}$ & $\begin{array}{c}\text { Clinical } \\
\text { Algorithm }\end{array}$ & Total \\
\hline $\begin{array}{l}\text { Number of } \\
\text { recruited GDPs }\end{array}$ & & 10 & 10 & 12 & 32 \\
$\begin{array}{lllll}\text { Number of } \\
\text { participating GDPs }\end{array}$ & Mean & 43 & 37 & 42 & 41 \\
Age in years & Median & 44 & 34 & 43 & 42 \\
& Range & $26-57$ & $29-48$ & $25-55$ & $25-57$ \\
Gender & Male & 7 & 4 & 5 & 16 \\
& Female & 3 & 1 & 1 & 5 \\
Relevant hospital & $>6$ months & 2 & 0 & 1 & 3 \\
experience & $<6$ months & 2 & 1 & 2 & 5 \\
& None & 6 & 4 & 3 & 13 \\
Years in general & Mean & 21 & 14 & 19 & 19 \\
dental practice & Median & 24 & 11 & 21 & 20 \\
& Range & $2-34$ & $6-25$ & $1-31$ & $1-34$ \\
\hline
\end{tabular}

anaesthesia/sedation or lack of surgical competence in primary care, were not considered. This was the approach adopted throughout the trial.

The periodontal criteria incorporated into the flowchart were based on Kugelberg's periodontal risk index. ${ }^{16}$ There were eight factors which, when present, scored one point each. The patient was said to be at sufficient risk from periodontal disease to justify lower third molar removal, if a score of four or more was achieved. Furthermore, according to Kugelberg, lower third molar removal should only be considered when a patient is 30 years old or less or when patients are suffering from periodontal symptoms from their lower third molars.

Several of the periodontal factors in the clinical algorithm were derived from radiographic measurements: depth of intrabony defect, sagittal inclination and follicle width. To increase the objectivity of these measurements a radiographic template was designed to be used with orthopantomograms (OPTs). It incorporated three measures together with a set of instructions. The template and instructions were printed on a reinforced transparent film so that it could be placed over each radiograph (Fig. 2)

Various prototypes of the radiographic template were evaluated using groups of 10 dental students who superimposed it on 20 OPTs. Each group was presented with the OPTs and was asked to measure and score (according to Kugelberg's criteria) the intrabony defect, sagittal inclination and follicle width for both the left and right lower third molars. No assistance was provided since the template was designed to be self-explanatory. Therefore, both the templates and the instructions for users were under scrutiny for reliability. The template was modified several times and re-tested until inter-observer reliability was greater than $80 \%$. The modified template, which was used in the trial reported here, is shown in figure 2.

Prior to the commencement of the trial, each GDP was visited by one of the researchers (RDG) and, if they were required to use one of the novel decision strategies, they were given a brief training session
Table 2 Numbers of patients by age, gender and social class

\begin{tabular}{|c|c|c|c|c|c|}
\hline \multicolumn{2}{|l|}{ Variable } & Control & $\begin{array}{l}\text { Neural } \\
\text { Network }\end{array}$ & $\begin{array}{l}\text { Clinical } \\
\text { Algorithm }\end{array}$ & Total \\
\hline \multicolumn{2}{|c|}{$\begin{array}{l}\text { No. of patients included } \\
\text { in the study }\end{array}$} & 47 (78\%) & 30 (97\%) & $30(88 \%)$ & $107(86 \%)$ \\
\hline \multicolumn{3}{|c|}{$\begin{array}{l}\text { No. of patients that } \\
\text { cancelled/did not attend their } \\
\text { HDS appointment }\end{array}$} & I (3\%) & $4(12 \%)$ & $18(14 \%)$ \\
\hline Age in years & $\begin{array}{l}\text { Mean } \\
\text { Median } \\
\text { Range }\end{array}$ & $\begin{array}{l}26 \\
23 \\
16-43\end{array}$ & $\begin{array}{l}26 \\
26 \\
18-35\end{array}$ & $\begin{array}{l}30 \\
30 \\
20-49\end{array}$ & $\begin{array}{l}27 \\
25 \\
16-49\end{array}$ \\
\hline Gender & $\begin{array}{l}\text { Male } \\
\text { Female }\end{array}$ & $\begin{array}{l}\text { II (23\%) } \\
36(77 \%)\end{array}$ & $\begin{array}{l}11(37 \%) \\
19(63 \%)\end{array}$ & $\begin{array}{l}10(33 \%) \\
20(67 \%)\end{array}$ & $\begin{array}{l}34(31 \%) \\
76(69 \%)\end{array}$ \\
\hline Social Class & $\begin{array}{l}\text { I } \\
\text { II } \\
\text { III } \\
\text { IV } \\
\text { V } \\
\text { nployed } \\
\text { nformation }\end{array}$ & $\begin{array}{c}2(4 \%) \\
3(6 \%) \\
19(41 \%) \\
2(4 \%) \\
1(2 \%) \\
19(41 \%) \\
1(2 \%)\end{array}$ & $\begin{array}{l}3(10 \%) \\
7(23 \%) \\
7(23 \%) \\
1(3 \%) \\
2(7 \%) \\
7(23 \%) \\
3(10 \%)\end{array}$ & $\begin{array}{l}5(17 \%) \\
6(20 \%) \\
3(10 \%) \\
1(3 \%) \\
3(3 \%) \\
9(30 \%) \\
6(20 \%)\end{array}$ & $\begin{array}{c}10(9 \%) \\
16(15 \%) \\
29(27 \%) \\
4(4 \%)\end{array}$ \\
\hline
\end{tabular}

(approx. 1/2 hour). During the visit, it was stressed to the GDPs that participation in the study must not interfere with their standard practice and that the decision-making strategies must run alongside, and not affect, their decisions to refer. It was further explained that, for the purpose of the trial, any patients that the GDP considered for referral should be included, regardless of whether or not the patient was actually referred. In addition, when there were a conflict between the decision made by the GDP and the novel decision strategy, the decision remained in the study.

Once the referral decision had been made utilising the practitioners' usual criteria, those GDPs using the novel decision strategies were instructed also to use either the neural network or clinical algorithm to generate a referral decision. If the GDP decided to refer a patient, relevant clinical data were recorded when the patient attended the hospital for consultation. If the GDP decided not to refer a patient, they were asked to record clinical data themselves.

\section{Evaluation of appropriateness of decisions to refer}

The gold standard used to judge the appropriateness of lower third molar removal decisions were the National Institute's of Health (NIH) criteria. ${ }^{1}$ Two experts, one oral surgery consultant and one researcher, who had previous experience in comparing clinical information with NIH criteria, conducted the evaluations. The oral surgery consultant had not been involved with any of the trial patients' treatment planning. Each of the referral decisions made using one of the three decision strategies was compared with the gold standard and further classified as being true positive or negative and false positive or negative, depending on whether the decision had been to refer the patient to hospital or not.

The GDPs' age, gender, qualifications, experience and years in practice, the patients' age, gender and social class, the prevalence of lower third molar pathology and appropriateness of the referral decisions were compared. The evaluation of the decision making ability of each of the groups was established by calculating sensitivity/specificity, accuracy and positive/negative predictive values.

Table 3 Prevalence of lower third molar disease

\begin{tabular}{|c|c|c|c|c|c|}
\hline & & Control & Neural Network & Clinical Algorithm & Total \\
\hline Pericoronitis & $\begin{array}{l}\text { No episodes } \\
\text { One episode } \\
\text { More than one episode }\end{array}$ & $\begin{array}{r}15(40 \%) \\
9(19 \%) \\
23(49 \%)\end{array}$ & $\begin{array}{r}10(33 \%) \\
9(30 \%) \\
11(37 \%)\end{array}$ & $\begin{array}{r}18(60 \%) \\
3(10 \%) \\
9(30 \%)\end{array}$ & $\begin{array}{l}43(41 \%) \\
21(20 \%) \\
43(40 \%\end{array}$ \\
\hline Caries & $\begin{array}{l}\text { In the lower third molar } \\
\text { In the lower second molar }\end{array}$ & $6(13 \%)$ & $\begin{array}{l}\text { I (3\%) } \\
\text { I (3\%) }\end{array}$ & $4(13 \%)$ & $\begin{array}{l}\text { II (10\%) } \\
\text { I (I\%) }\end{array}$ \\
\hline $\begin{array}{l}\text { Periodontal disease } \\
\text { (Kugelberg's index) }\end{array}$ & $\begin{array}{l}\text { Score } 4 \text { or more and } \\
\text { over } 30 \text { years old }\end{array}$ & $9(19 \%)$ & $5(17 \%)$ & $3(10 \%)$ & $17(16 \%)$ \\
\hline
\end{tabular}


Table 4 Comparison of patient referral decisions with the gold standard recommendations

\begin{tabular}{lccc}
\hline & Control & Neural Network & Clinical Algorithm \\
\hline True positive & $37(79 \%)$ & $9(30 \%)$ & $9(30 \%)$ \\
True negative & $2(4 \%)$ & $11(37 \%)$ & $13(43 \%)$ \\
False positive & $7(15 \%)$ & $3(10 \%)$ & $1(3 \%)$ \\
False negative & $1(2 \%)$ & $7(23 \%)$ & $7(23 \%)$ \\
$\begin{array}{l}\text { Correct decisions } \\
\text { Incorrect decisions }\end{array}$ & $39(83 \%)$ & $20(67 \%)$ & $22(73 \%)$ \\
No. of patients requiring & $38(81 \%)$ & $16(33 \%)$ & $8(26 \%)$ \\
lower third molar removal & & & $16(53 \%)$ \\
No. of patients not & $9(19 \%)$ & $14(47 \%)$ & $14(47 \%)$ \\
requiring lower third molar & & & \\
removal & & & \\
\end{tabular}

\section{Results}

Although 32 GDPs were recruited, only 20 GDPs actually made a referral decision during the period of the study (control=9; neural network $=5$; clinical algorithm $=6$ ). Characteristics of the GDPs are set out in table 1. The age of the GDPs ranged from 25-57 years: mean age was 41 years. There were more male than female practitioners. Thirty eight per cent of the GDPs had some practical experience in a hospital oral surgery department. There were similarities between the three groups in terms of gender and experience in hospital oral surgery, but these could not be evaluated statistically as there were too few GDPs to allow chi square analyses. The GDPs in the neural network group were younger and had worked for less time in practice than practitioners in the other two groups. However, statistical analyses using the Kruskal-Wallis test revealed that these differences between their ages $\left(\chi^{2}=0.62 ; \mathrm{df}=2 ; \mathrm{p}=0.73\right)$ and primary care experience $\left(\chi^{2}=1.11 ; \mathrm{df}=2 ; \mathrm{p}=0.57\right)$ were not significant.

The trial included a total of 125 referral decisions, of which 66 were decisions to refer to the hospital dental service (HDS) and 41 were decisions not to refer. Eighteen patients who were referred did not attend their hospital appointment and, therefore, could not be included in the evaluation. This left a total of 107 referral decisions. There was a significant difference between the three groups in terms of the number of referral and non-referral decisions $\left(\chi^{2}=36.49\right.$; $\mathrm{df}=2 ; \mathrm{p}<0.001)$. Variation was greatest in relation to control group decisions compared with the neural network $\left(\chi^{2}=26.54 ; \mathrm{df}=1\right.$; $\mathrm{p}<0.001)$ and the clinical algorithm $\left(\chi^{2}=31.77 ; \mathrm{df}=1 ; \mathrm{p}<0.001\right)$. In both comparisons, a greater proportion of patients in the control group were referred. However, the difference, in terms of the proportion of referral/non-referral decisions, between the neural network and clinical algorithm was not significant $\left(\chi^{2}=0.29 ; \mathrm{df}=1\right.$; $\mathrm{p}=0.79)$.

The demographic characteristics of the 107 patients for whom clinical details were collected are summarised in table 2 . The mean age of the patients was 26 years: the majority were under 35 years ( 94 $\%)$. There was no evidence of a difference between the three groups in terms of gender $\left(\chi^{2}=1.77 ; \mathrm{df}=2 ; \mathrm{p}=0.41\right)$ but, according to the Kruskal-Wallis analysis, the patients in the control (mean age $=26$ years) and neural network (mean age $=26$ years) groups were slightly younger than the patients in the clinical algorithm group (mean age $=30$ years) $\left(\chi^{2}=16.74 ; \mathrm{df}=2 ; \mathrm{p}<0.001\right)$.

Collectively, the 107 patients had 202 lower third molars. The

Table 5 Evaluation of the referral decision-making ability of each group on an individual patient basis

\begin{tabular}{lccc}
\hline & Control & Neural Network & Clinical Algorithm \\
Accuracy & 0.83 & 0.67 & 0.73 \\
Sensitivity & 0.97 & 0.56 & 0.56 \\
Specificity & 0.22 & 0.79 & 0.93 \\
Positive predictive value & 0.84 & 0.75 & 0.90 \\
Negative predictive value & 0.66 & 0.61 & 0.65
\end{tabular}

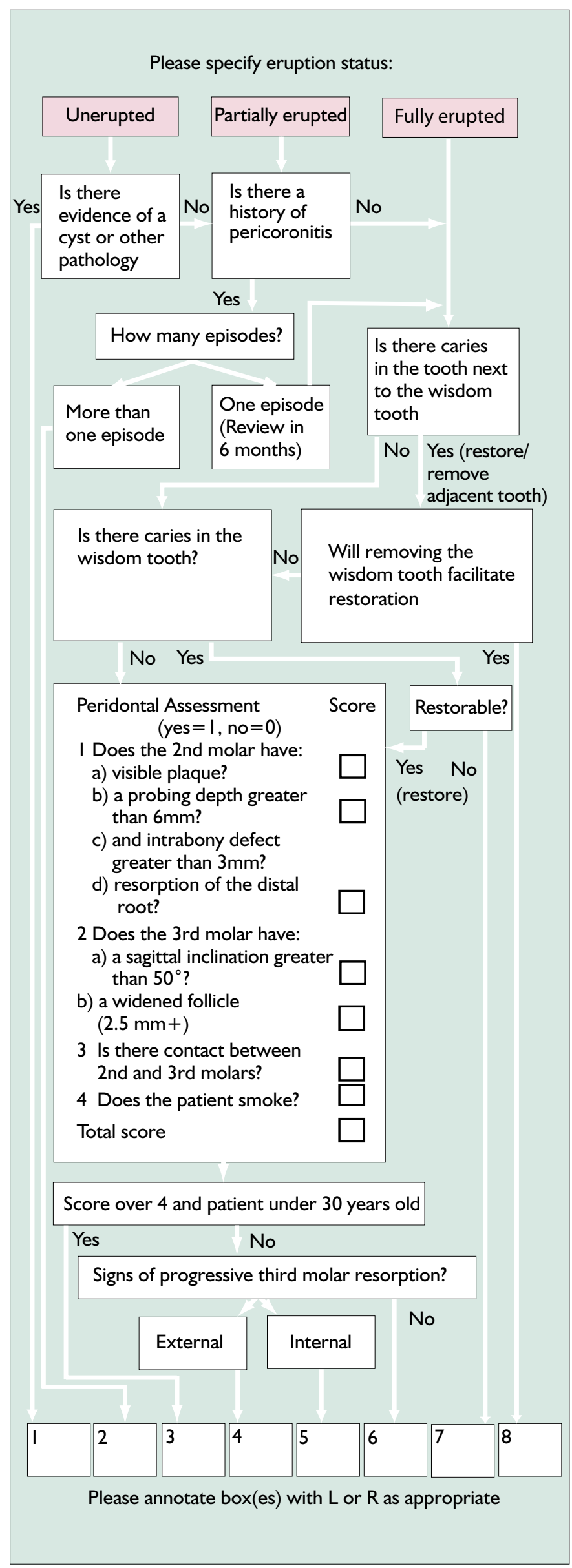

Fig. I Clinical algorithm to assist lower third molar referral decisions. I-5,7,8 = Recommendations to remove; Recommendation not to remove. 


\section{Intrabony defect}

\section{Radiographic template}

- Place line A on the bone crest, distal to the adjacent molar on the radiograph

- If line B lies: A

a) above the lower limit of the bony pocket, score = I

b) below or on the lower limit of the bony pocket, score $=0$ e.g.

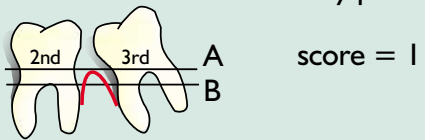

\section{Sagittal inclination}

If:

the mandibular third molar is disto-angular, score $=0$

Or:

if the mandibular third molar is vertical (no angulation), score $=0$

Or:

if the third molar is mesio-angular, follow these instructions:

I Select the diagram that best represents the angular relationship between the third and second molars.

2 Score according to the numbers beneath the most appropriate diagram below:

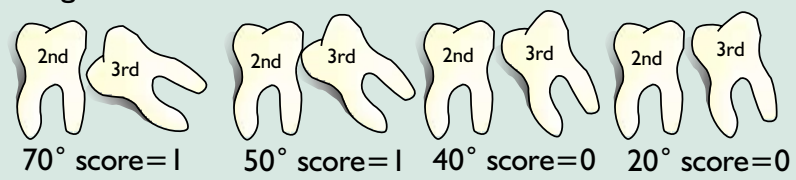

Tip: Place the template over the teeth on the radiograph to give a clearer indication.

Pathologically widened follicle

- Take a measure at the most widened area of the follicle.

- Place a line A at the tooth perimeter

- If the outer edge of the follicle lies:

a) inside line $B$, score $=0$

b) outside or on line B, score $=1$

e.g.
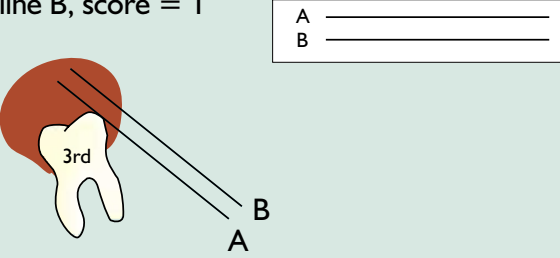

score $=1$ A

Fig. 2 Radiographic template for periodontal assessment of lower third molars, according to Kugelberg. ${ }^{16}$ (not to scale)

majority in all three decision groups were partially erupted (60\%) or unerupted $(26 \%)$ and a small minority were absent $(5 \%)$ or fully erupted $(9 \%)$. The incidence of the various diseases in each of the three groups can be seen in table 3 .

Chi square analyses revealed that the distribution of patients with or without pathology associated with their lower third molars varied significantly between the control and clinical algorithm groups $\left(\chi^{2}=10.95 ; \mathrm{df}=1 ; \mathrm{p}=0.001\right)$ but not between the control and neural network groups $\left(\chi^{2}=1.46 ; \mathrm{df}=1 ; \mathrm{p}=0.35\right)$ or the neural network and clinical algorithm groups $\left(\chi^{2}=3.59 ; \mathrm{df}=1 ; \mathrm{p}=0.1\right)$. The principal difference was that there were more patients who had disease than those who did not in both the control $(87 \%)$ and neural network (77\%) groups, whereas almost half (47\%) of patients considered by GDPs using the clinical algorithm did not have diseases associated with their lower third molars.

However, the distribution of correct and incorrect referral decisions did not vary significantly between the three groups $\left(\chi^{2}=2.78\right.$; $\mathrm{df}=2 ; \mathrm{p}=0.25$ ) (Table 4). The two novel decision strategies made the same number of true positive and false negative decisions. However, the clinical algorithm made more true negative referral decisions than the neural network and the neural network made more false positive referral decisions than the clinical algorithm.

The control strategy (i.e. existing practice) was the most sensitive and accurate of the three decision strategies. However, the control practitioners were also most likely to refer patients that did not require lower third molar removal (Table 5). Both of the novel decision strategies had the same level of sensitivity $(0.54)$. However, the clinical algorithm displayed the greatest ability to detect those patients for whom, according to the criteria, lower third molar removal was not required.

The predictive values suggest that $90 \%$ of the decisions to refer made by the clinical algorithm were correct. Conversely, the probability that a decision not to refer was correct ranged from $0.6-0.7$ for each group, with the control group having the highest value $(0.66)$ and the neural network having the lowest value (0.61).

\section{Conclusion}

The control GDPs (who only made decisions in the traditional manner) were more inclined than either of the two novel decision groups to refer patients. As a consequence, these GDPs referred a number of patients inappropriately. In contrast, use of the novel decision strategies, particularly the clinical algorithm, led to fewer unnecessary referrals. Conversely, the novel strategies were less able to recognise when a referral was necessary.

The majority of the control GDPs' referral decisions were correct. However, as few patients were included who did not require lower third molar removal, this level of accuracy largely applied to decisions to refer, rather than decisions not to refer. This also explains the control GDPs' relatively low specificity values. Taking into account the proportion of patients that actually required or did not require lower third molar removal, the control GDPs were less able to predict the need for surgery than was suggested by the sensitivity values and better able to predict when a patient did not require surgery than was suggested by the specificity values. In contrast to the control GDPs, both of the novel decision strategies were better at detecting patients who did not require third molar removal than detecting those who did. Both novel strategy groups' level of accuracy was lower than that of the control GDPs', the clinical algorithm being more accurate and more able than the neural network to detect those patients that did not require lower third molar removal.

The effects of inappropriate referral decisions at either the primary or secondary level of care have yet to be measured. The result of a false positive decision is that a patient will be referred and will probably then attend a hospital oral surgery clinic unnecessarily. This inevitably causes the patient avoidable costs. Edwards ${ }^{17} \mathrm{calcu}-$ lated that, on average, a consultation costs each patient $\mathfrak{E} 10.96$. This takes into account travel, parking fees and arrangement for time off work/studies or time away from home. There are further implications as an unnecessary referral could, potentially, increase the likelihood of unnecessary surgery. Conversely, an increased rate of false negative decisions could lead to avoidable symptoms and possibly even avoidable loss of a second molar in the case of failure to detect distal caries or periodontal disease mesial to a third molar. The importance of this is open to question however, since diseases associated with third molars often give rise to symptoms that lead patients to seek help. Cost-effectiveness analyses have supported a non-interventionist approach for patients who are disease free, from both health care providers' and consumers' perspectives. ${ }^{4}$

This study has attempted to provide evidence that could be used to improve referral practice. Whilst some methodological problems were encountered, particularly a reluctance on the part of the GDPs to participate and the patterns of referring behaviour of each individual GDP, the control GDPs made few inappropriate referrals. However, when GDP referral decisions were incorrect they usually resulted in patients being referred unnecessarily. The opposite was true for both the neural network and clinical algorithm, although 
the clinical algorithm was generally more accurate.

The computer-based neural network presented a number of problems both in the appropriateness of its decision-making and reluctance of the GDPs to use it, particularly older practitioners. The latter might be overcome in time as computers and computerbased decision aids become more widespread but this trial suggests that this method needs further refinement before it could outperform alternative strategies. Low GDP response rates to approaches to take part in clinical research are not uncommon. Recently, Renton and McGurk attempted to evaluate a novel referral approach for day case oral surgery. ${ }^{18}$ Of the 200 GDPs they approached, only 12 actually participated in the study. This was attributed to poor marketing techniques, time constraints and medico-legal implications for the GDPs. The overall inclusion rate for this study was higher $(18 \%)$, which may have resulted from the visit by a research worker (RDG) to each practice, which provided an opportunity for discussion.

On the basis of these findings, the clinical algorithm combined with existing practice is the best option in a general dental practice setting. This is the case both on the grounds of accuracy, sensitivity and specificity and also on the grounds of practical implementation. For example, the algorithm can easily be incorporated into a standard referral letter. However, since use of the algorithm is associated with a tendency not to refer some patients when surgery is justified, regular review is important so that this small minority of patients could be referred subsequently. Further research is needed to establish if less complex, but equally or more efficient versions of the algorithm could be developed, perhaps by removing the periodontal index and, therefore, the need for a radiographic template.

We are grateful to all the dental practitioners who took part in this study and to the PPP Medical Trust for project funding.

1 Guralnick W C, Laskin D M. NIH consensus development conference for removal of third molars. J Oral Surg 1980; 38: 235-236.

2 Tulloch J F C, Antczak-Boukoms A. Decision analysis in the evaluation of clinical strategies for the management of mandibular third molars. J Dent
Ed 1987; 51: 652-660.

3 Brickley M R, Kay E, Shepherd J P, Armstrong R A. Decision Analysis for Lower-third-molar Surgery. Med Dec Mak 1995; 15: 143-151.

4 Edwards M J, Brickley M R, Goodey R D, Shepherd J P. The cost, effectiveness and cost effectiveness of removal and retention of asymptomatic, disease free third molars. Br Dent J 1999; 187: 380-384.

5 National Institute of Clinical Excellence. Guidance on the removal of Wisdom Teeth. London: NICE, 2000.

6 Yablon P, Wolf M C, Maykow K P. Third Molar Teeth: Differing Concepts of Oral Surgeons and Other Dentists. New York State J 1988; 54: 27-31.

7 Knutsson K, Brehmer B, Lysell L, Rohlin M. General dental practitioners' evaluation of the need for the extraction of asymptomatic mandibular third molars. Community Dent Oral Epidemiol 1992; 20: 347-350.

8 Lysell L, Brehmer B, Knutsson K, Rohlin M. Judgement on removal of asymptomatic mandibular third molars: influence of the perceived likelihood of pathology. Dent Max Radiol 1993; 22: 173-177.

9 Joynson O B, Williams S L, Brickley M R, Shepherd J P. Lower third molar treatment planning ability of general dental practitioners and oral oral maxillofacial surgeons using receiver operating characteristics methodology. Brit Dent J 1996; 181: 411-415.

10 Knutsson K, Brehmer B, Lysell L, Rohlin M. Judgement of removal of asymptomatic mandibular third molars: influence of position, degree of impaction, and patient's age. Acta Odontol Scand 1996; 54: 348-354.

11 Kostopoulou O, Brickley M R, Shepherd J P, Knutsson K, Rohlin M. Agreement between practitioners concerning removal of asymptomatic third molars. Community Dent Health 1997; 14: 129-132.

12 Jones C M, O'Brien K, Blinkhorn A S, Rood J P. Dentists' agreement on treatment of asymptomatic impacted third molar teeth. Br Med J 1998; 315: 1204.

13 Kostopoulou O, Brickley M R, Shepherd J P, Newcombe R G, Knutsson K, Rohlin M. Intra-observer reliability regarding removal of asymptomatic third molars. Br Dent J 1998; 184: 557-558.

14 Worrall S F, Riden K, Haskell R, Corrigan A M. UK National Third Molar project: the initial report. Br J Oral Maxillofac Surg 1998; 36:14-18.

15 Brickley M R, Shepherd J P. Performance of a Neural Network Trained to Make Third-Molar Treatment-Planning Decisions. Med Dec Mak 1996; 16: 153-160.

16 Kugelberg C F. Third molar surgery. Curr Opin Dent 1992; 2: 9-16.

17 Edwards M J. A decision analysis to assess the cost, effectiveness and costeffectiveness of surgical removal and non surgical treatment in the management of mandibular third molars. MPhil. U. Of Wales, 1998.

18 Renton T, McGurk M. Direct referral daycase oral surgery for dental practitioners: a pilot investigation. Br Dent J 1999; 186: 334-337. 